\title{
ANALYSIS OF PRESSURE AND FLOW PATTERNS ON TWO-PHASE (AIR-WATER) FLOW IN HORIZONTAL PIPES WITH SCALLOPED GROOVE
}

\author{
Gufron Saiful Bachri ${ }^{1)}$, Rudy Soenoko ${ }^{2)}$, Denny Widhiyanuriyawan ${ }^{3)}$ \\ Program Studi Megister Teknik Mesin Fakultas Teknik \\ Universitas Brawijaya \\ Email : ${ }^{1}$ gufron.bachri@yahoo.com
}

\begin{abstract}
The groved surfaces are widely researched to reduce pressure drop and control a flow on the surface. In applicative fluids flow is turbulen. So, the grove addition capable of affecting the boundary layer condition near the wall pipes. The purpose of this researched is to analyse the impact of the number of grooves in pipes against the pressure drop and the occurred flow patterns. In this researched, we used 3 pipes, which total of grooves were 4,8,16 and the pipes without grooves that used as comparator. The observed flow was two phases flow (air-water). The researched pipes used acrylic pipes with diameter of 1 inch and length of $100 \mathrm{~cm}$ with the groove used was type of scalloped groove. Pressure drop occurs in all of the grooves ; 4,8, and 16. The highest pressure drop decrease occurred in groove 16. When the air debit was getting bigger, the bubbly was reduced and followed by the emergence of slug flow. The changes in water debit in the decrising of pressure drop in every single of drop, shows the dencity between the bubbly and slug flow that firmed.
\end{abstract}

Keywords:Two Phase Flow, Air-Water, Horizontal pipes, Groove, Slug Flow.

\section{Pendahuluan}

Dalam kehidupan sehari-hari aliran fluida yang terjadi di dalam perpipaan tidak hanya berupa aliran satu fase saja, akan tetapi juga sering terjadi aliran multifase. Aliran multifase adalah aliran yang fasenya teridiri dari padat, cair dan gas yang saling berinterkasi. Contoh pengaplikasian pada aliran multifase diantaranya adalah sistem tenaga, sistem perpindahan panas, sistem pelumasan, maupun sistem biologi. Aliran multifase bisa berupa aliran dua fase ataupun aliran tiga fase. Pada aliran dua fase sendiri adalah aliran yang teridiri dari dua fase berbeda, salah satunya adalah aliran dua fase udara-air.

Fluida yang mengalir melalui sebuah saluran dengan panjang tertentu mengalami suatu hambatan. kerugian energi berupa penurunan tekanan (pressure drop) yang disebabkan oleh mayor losses akibat dari gesekan sepanjang dinding pipa maupun minor losses akibat perubahan bentuk dari saluran dan juga tergantung berdasarkan koefisien gesek pipa tersebut

Hambatan yang dihubungkan dengan energi yang digunakan untuk menggerakkan fluida dari suatu tempat ke tempat lain sering disebut pressure drag. Di alam terdapat bentuk dan cara untuk mengurangi drag pada aliran fluida, dibuktikan dengan efisiensi pada pergerakan ikan lumba-lumba dan hiu. Struktur kulit memudahkan hiu untuk berenang dengan mengurangi drag saat melewati air. Lapisan dalam skala kecil yang melindungi kulit hiu disebut dengan dermal denticle (skin teeth), yang memiliki bentuk mirip dengan alur kecil. Bentuk lapisan kulit ini yang kemudian mulai banyak dimanfaatkan dalam kehidupan manusia. 
Alur groove adalah bentuk longitudinal sepanjang searah streamwise yang berfungsi untuk mengurangi drag dengan cara mengubah near wall flow structure pada sebuah bentuk. Teknik control aliran untuk pengurangan drag ini sangatlah penting dalam aplikasi engineering.

Grüneberger and Hage, (2011), Fungsi groove adalah memberikan penundaan transisi ke turbulen dari lapisan batas laminar disebabkan interaksi antara alur longitudinal dengan hairpin vortices untuk memperlambat pertumbuhannya (Choi, 2000). Pengoptimalisasian pengurangan drag dapat dilakukan dengan memaksimalkan protrusion height dari alur untuk aliran longitudinal dan cross flow. Pengukuran shear stress secara langsung pada alur dengan trapezoidal grooves sejajar dengan arah aliran fluida pada fully developed turbulen channel flow menghasilkan penurunan drag sebesar $7.6 \%$ pada dimentionless spacing s ${ }^{+}=0.3-24$.

Sunu et.al., (2016) Penelitian pada internal flow dengan menggunakan aliran satu fase fluida air yang dilakukan pada pipa beralur dengan diameter $2,6 \mathrm{~cm}$ dan panjang $100 \mathrm{~cm}$, pada pipa dengan rectangular grove (alur 2, 8, 12,32) terjadi penurunan drag, friction, kecepatan radial, skewness factor bernilai positif, diameter vortex lebih besar dari lebar alur dan fluida tidak mengalami perputaran selama mengalir dari upstream ke downstream.

Dari uraian tersebut dan melihat pentingnya penelitian. Maka perlunya melakukan penelitian lebih lanjut tentang fenomena aliran dalam pipa, dengan bentuk groove dan jenis aliran berbeda. Diperlukanlah gambaran berbeda selain daripada aliran satu fase maka perlunya melakukan penelitian dalam bentuk aliran dua fase dengan pipa scalloped groove. Jenis groove yang digunakan adalah scalloped groove. Scalloped groove adalah alur lengkung sepanjang dalam pipa. Kita ketahui bahwa ada beberapa bentuk groove diantaranya sawtooth (gigi lancip), rectangular (persegi panjang) dan scalloped (gigi lengkung). Dipilihnya scalloped groove karena memiliki kelebihan tanpa adanya sudut pada bentuk alurnya, yang memungkinkan resiko keretakan pada pipa.

\section{Metodologi Penelitian}

Penelitian ini dilakukan dengan metode eksperimental yaitu melakukan pengukuran langsung dan tak langsung.
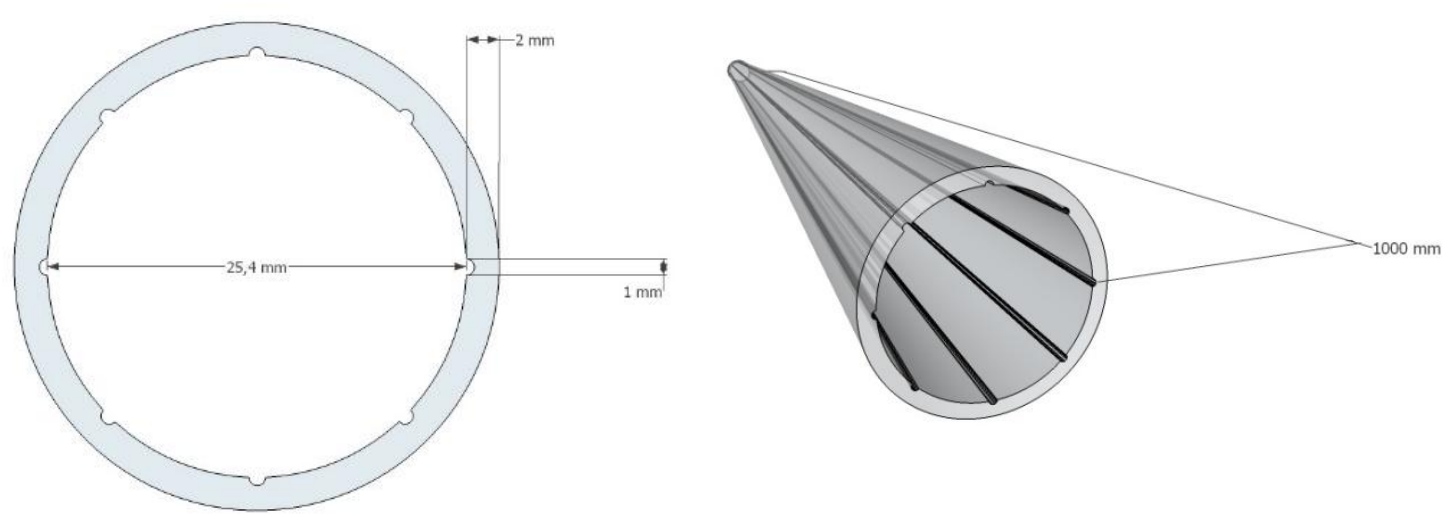

Gambar 1. Bentuk pipa dengan scalloped groove 


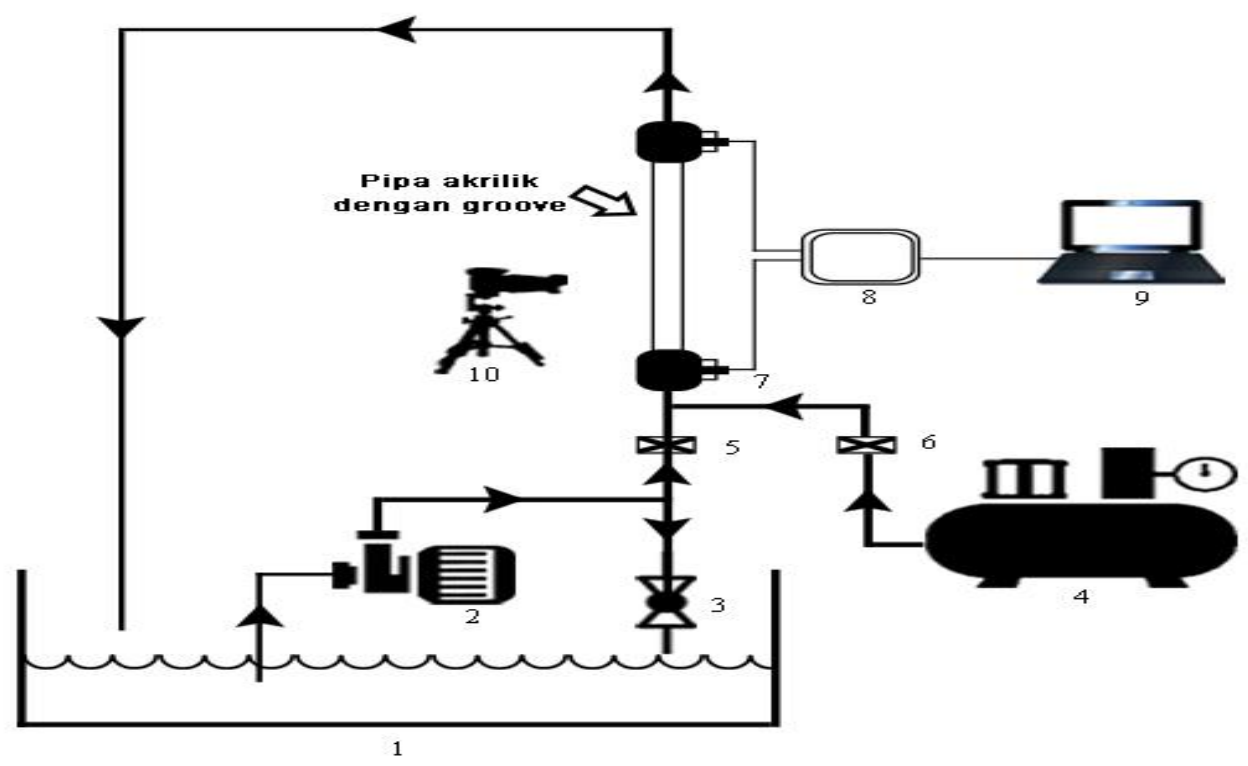

Gambar 2. Instalasi Penelitian

Keterangan :

1. Tandon air

2. Pompa air

3. Valve aliran air

4. Kompressor

5. Flowmeter digital
6. Rotameter

7. Pressure sensor

8. Data logger

9. Laptop

10. Kamera dan tripod

Air sebagai fase cair pada aliran dua fase disuplai dengan pompa dan udara disuplai dengan kompresor. Air dari tangki input dan diatur laju alirannya menggunakan by-pass dan kemudian laju aliran diukur menggunakan flow meter. Udara juga diukur laju aliran menggunakan katup berdasarkan nilai dari flow meter. Kedua aliran tersebut bercampur pada mixer. Kedua aliran membentuk aliran dua fase yang melalui seksi pipa uji. Penelitian dilakukan dengan variasi debit air 14, 16, 18 dan 20 liter/menit. Pada Sedangkan variasi debit udara $0.5,1,1.5,2$, dan 2.5 liter/menit. Data tekanan ditangkap oleh pressure sensor pada sisi inlet dan outlet pipa. Data tekanan diukur perdetik selama 1 menit. Aliran air kemudian kembali ke tangki input, sehingga membentuk siklus. Hasil pengamatan ditangkap melalui kamera berkecepatan tinggi pada sisi tengah pipa uji.

Peneliti sudah melakukan sample pengujian awal yang didapatkan bahwa aliran mulai terbentuknya bubble adalah pada debit 14 liter/menit. Dan total bubble terbentuk adalah pada debit 15 liter/menit. Kemampuan groove dalam memecah aliran terhadap bubble yang terbentuk, menjadikan alasan penelitian yaitu pada debit diatas 14 liter/menit pada kondisi turbulen. Data tekanan diukur perdetik selama 1 menit berdasarkan sensor defential MPX10DP yang kemudian di olah oleh Arduino data logger, yang berfungsi mengubah data analog menjadi digital. 


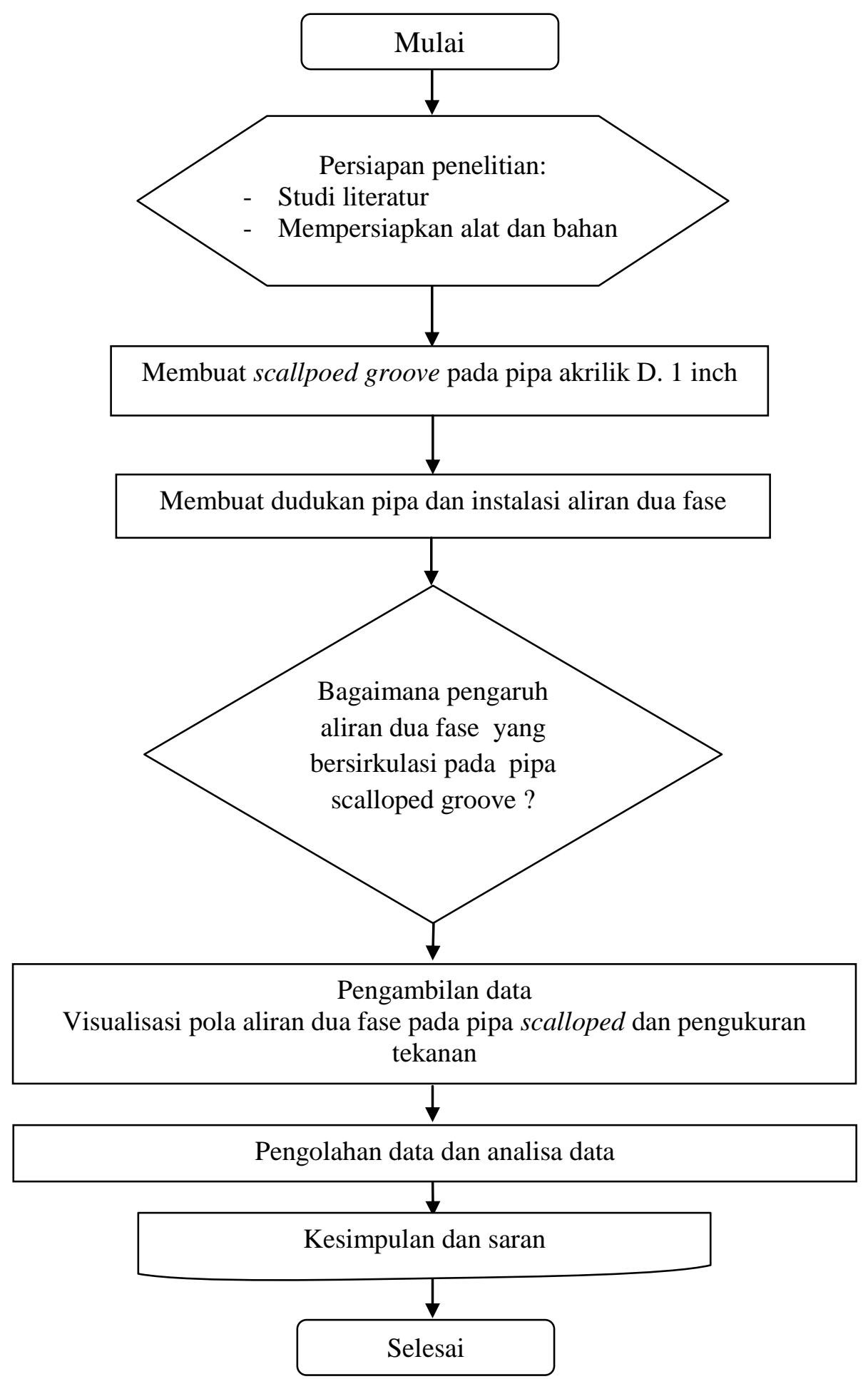

Gambar 3. Diagram Alir Penelitian

\section{Hasil dan Pembahasan}

Data pressure digambarkan berupa grafik rata-rata pressure drop pada setiap alur. Data tersebut dikelompokkan berdasarkan pada debit 14, 16, 18, dan 20 liter/menit. 

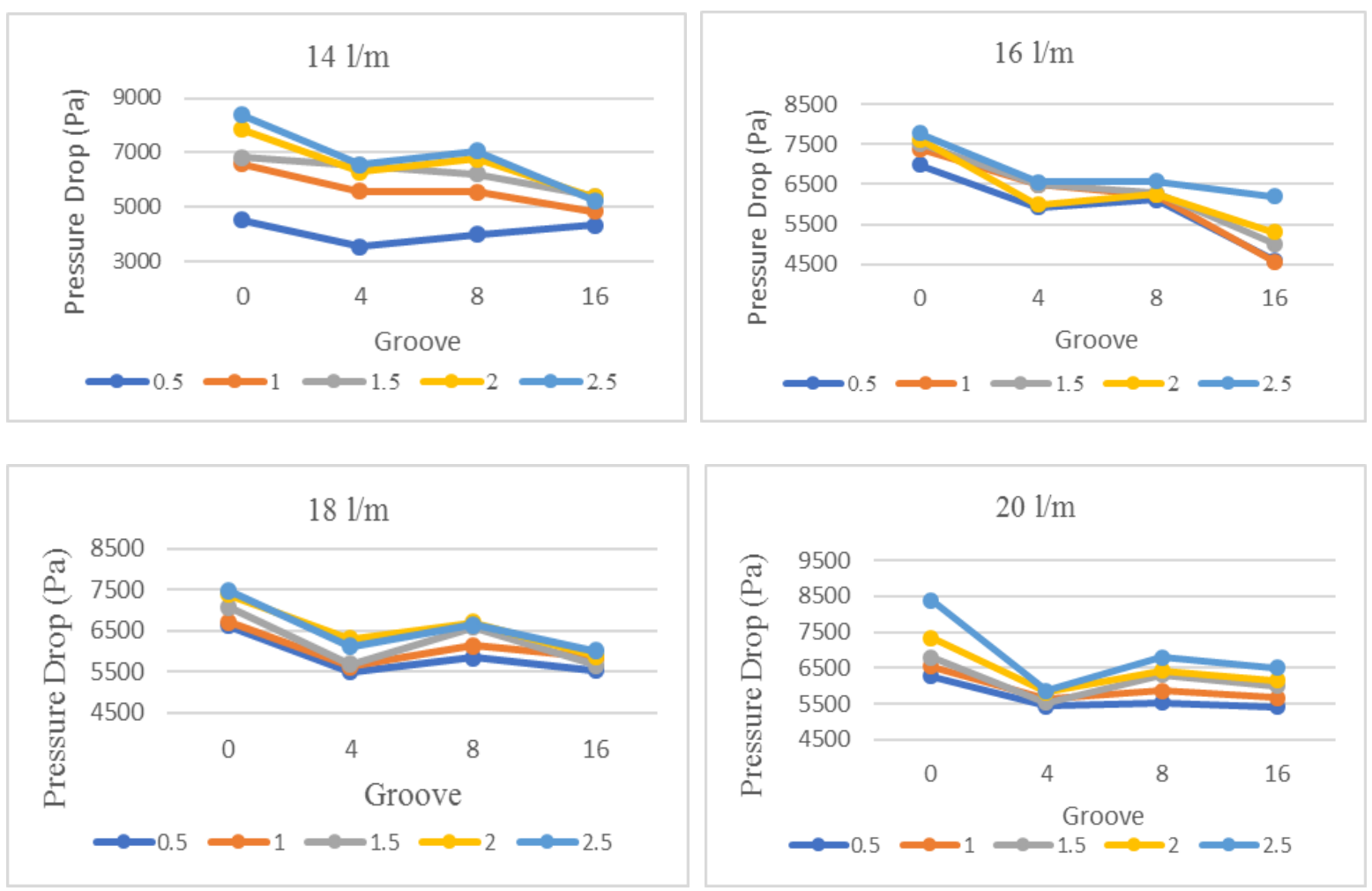

Gambar 4. Data Pressure Pada Tiap Aliran

Pada gambar 4 pipa dengan alur 0, 4, 8 dan 16 secara jelas menunjukkan nilai penurunan pressure drop. Pada tiap-tiap debit, peranan groove mampu mengurangi pressure drop yang terjadi. Pada debit air 14 dan 16 liter/menit, nilai pressure drop tertinggi terjadi pada groove 16, diikuti groove 4 kemudian 8 . Pada debit 18 dan 20 liter/menit nilai penurunan pressure drop tertinggi terjadi pada groove 4 dan di ikuti groove 16 kemudian 8 . Semakin tinggi debit air dalam pipa, semakin turun nilai pressure drop pada titik groove 4 , dan di ikuti naiknya pressure drop pada groove 16.
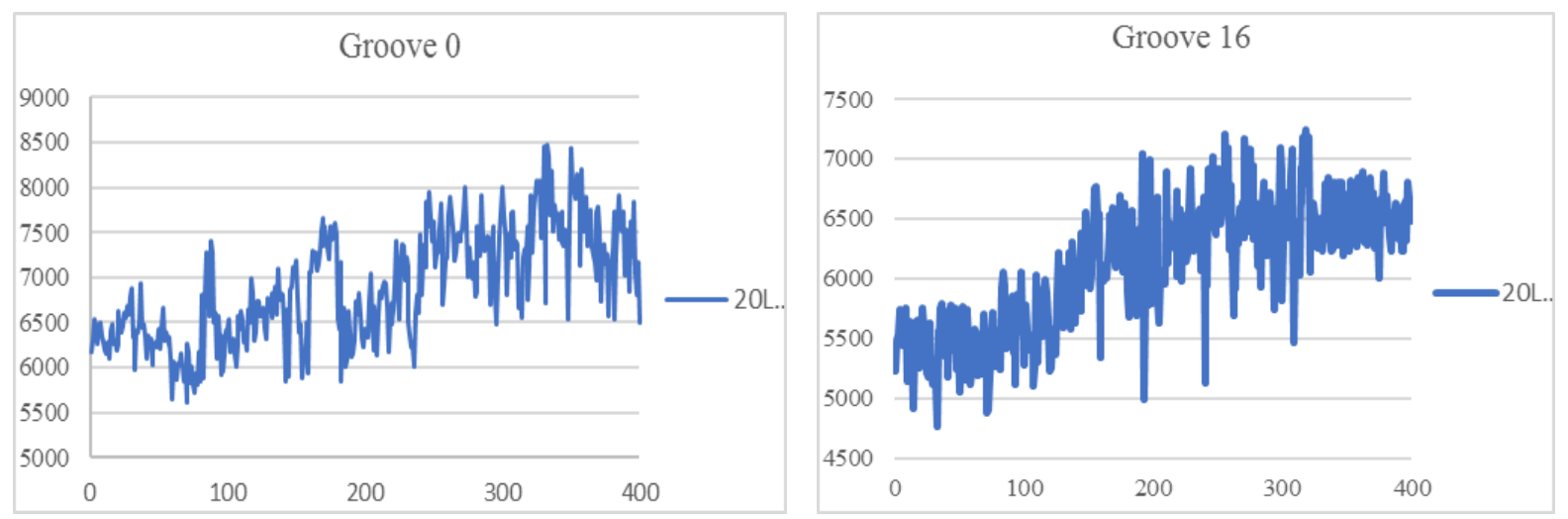

Gambar 5. Data signal Pressure drop pada debit 20 1/menit dikondisi groove 0 dan 16.

Pada gambar 5 dijelaskan tentang pressure drop sebagai fungsi nilai data signal fluktuasi. Pada gambar bahwa naiknya groove mampu meredam nilai fluktuasi getaran pada aliran. Pada groove 0, getaran lebih acak serta kerenggangan pada garis signal. Pada groove 16, garis signal terlihat lebih rapat dan di ikuti dengan fluktuasi yang lebih rendah. 

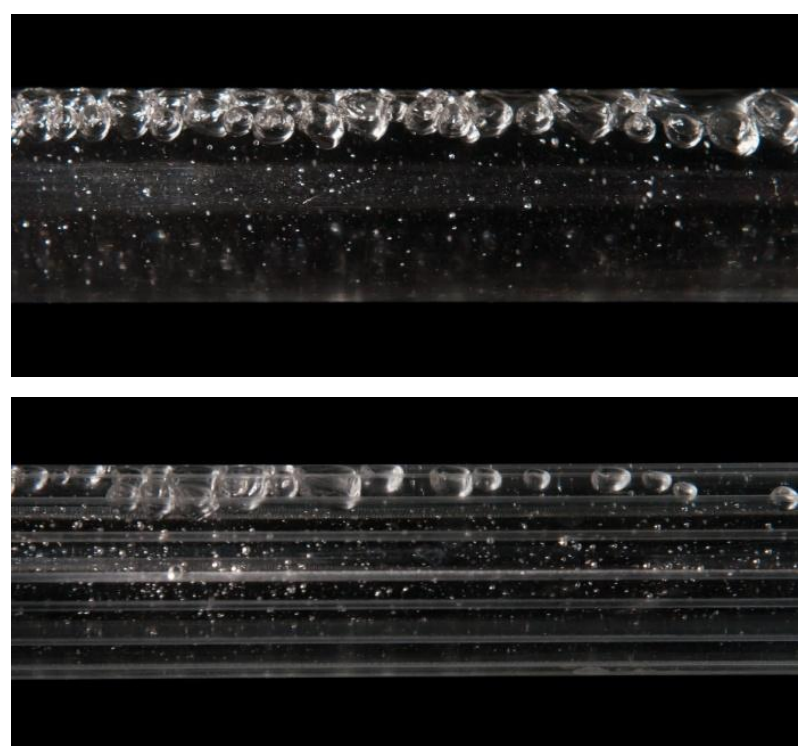

Gambar 6. Pola aliran pada debit 20 1/menit dikondisi udara 0.5 1/menit groove 0 dan 16

Pada dasarnya semakin rendah debit udara maka bentuk udara adalah bubble. Hal ini di ikuti dengan tercapai pecahnya udara menjadi bubble adalah pada nilai kenaikan debit air. Begitu halnya jika kenaikan pada debit udara maka kerapatan udara yang terbentuk semakin banyak, yaitu terbentuknya slug. Gambar 6 menunjukkan pola aliran antara groove 0 dengan groove 16. Dimana terlihat pada groove 0 dan groove 16 , bentuk aliran yang timbul hanyalah bubble. Tentu dengan debit udara rendah yaitu 0,5 liter/menit. Groove berperan dalam memecah bentuk bubble. Terlihat Bubble pada groove 0 memiliki struktur bubble yang lebih rapat dengan bubble yang lain. Sedangkan pada groove 16, memiliki struktur bubble yang lebih menyebar dan kecil. Hal ini akibat pengaruh groove sebagai fungsi pemisah menyatunya bubble yang nantinya membentuk slug flow.
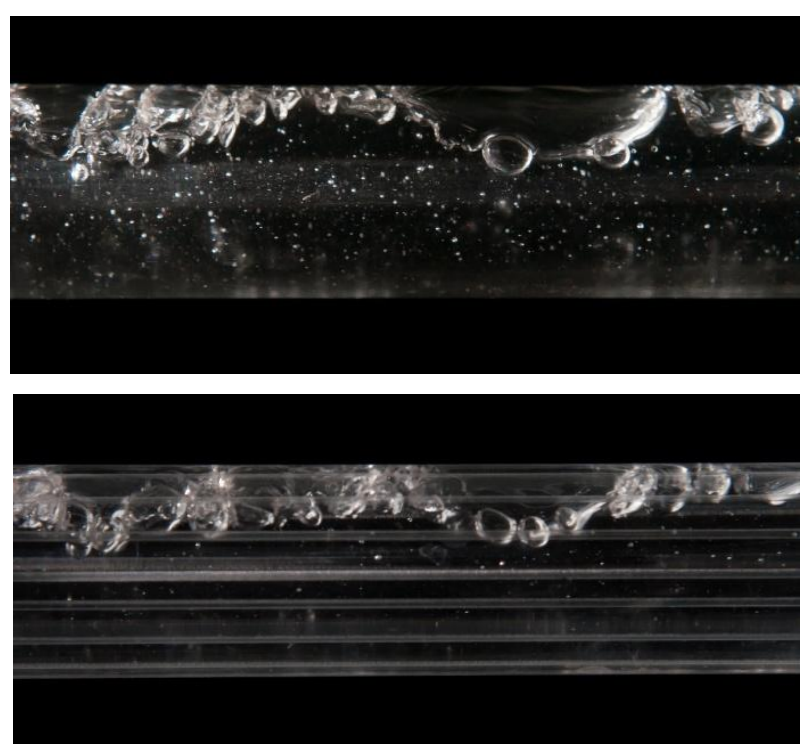

Gambar 7. Pola aliran pada debit 20 1/menit dikondisi udara 2.5 1/menit groove 0 dan 16.

Kenaikan udara pada setiap debit air, maka kerapatan udara yang terbentuk juga semakin banyak, dan timbullah aliran slug. Aliran udara yang sebelumnya kecil yaitu bubble menyatu, dan semakin rapat dan berkurang dengan di ikuti timbulnya slug. Sebagai gambaran dasar bahwa tidak akan timbul bubble pada kondisi udara tinggi. Gambar 7 pada debit udara tertinggi $2.5 \mathrm{l} / \mathrm{m}$. Terlihat pada gambar terjadi adanya bubble dan slug. Pada groove 0 , 
memiliki bentuk bubble yang lebih rapat, dan slug yang lebih besar. Sedangkan pada groove 16 memiliki bubble yang cenderung pada bentuk bulatan kecil dan slug yang lebih kecil di banding tanpa groove. Dengan adanya groove mampu mengakomodasi bentuk slug besar untuk memecahnya, karena slug sendiri menciptakan kekuatan besar untuk merubah arah pada belokan pipa.

\section{Kesimpulan}

Dari hasil penelitian ini dapat diambil kesimpulan bahwa :

1. Pengaplikasian aliran dua fase pada pipa scalloped groove berbahan akrilik mampu memberikan gambaran bentuk aliran udara didalamnya.

2. Terjadi penurunan pressure drop pada semua groove 4,8 dan 16. Semakin besar groove maka bentuk bubble dan slug semakin padat. Bubble yang terbentuk lebih memisah serta ukuran slug flow yang terjadi lebih kecil. Dimana fungsi groove sebagai pemecah udara.

3. Pressure drop aliran dua fase melalui scalloped groove berbanding lurus dengan fluktuasi pressure yang terjadi. Dimana nilai fluktuasi semakin kecil.

\section{Ucapan Terimakasih}

Menyampaikan ucapan terima kasih yang setinggi-tingginya kepada:

1. Bapak Prof. Dr. Ir. Rudy Soenoko, M.Eng.Sc. Universitas Brawijaya Malang.

2. Dr. Eng. Denny Widhiyanuriyawan, ST., MT. Universitas Brawijaya Malang

\section{Daftar Pustaka}

[1] Sunu, et al. (2016). Turbulent Flow Characteristics in Internally Grooved Pipe. Australian Journal of Basic and Applied Sciences

[2] Dean, B., \& Bhushan, B. (2010). Shark-skin surfaces for fluid-drag reduction in turbulent flow: a review. Philosophical Transactions of the Royal Society A: Mathematical, Physical and Engineering Sciences, 368(1929), 4775-4806.

[3] Ahmadi-Baloutaki, M., Carriveau, R., \& Ting, D. K. (2013). Effect of free-stream turbulence on flow characteristics over a transversely-grooved surface. Experimental Thermal and Fluid Science, 51, 56-70.

[4] Aroonrat, K., Jumpholkul, C., Leelaprachakul, R., Dalkilic, A. S., Mahian, O., \& Wongwises, S. (2013). Heat transfer and single-phase flow in internally grooved tubes. International Communications in Heat and Mass Transfer, 42, 62-68.

[5] Huang, S. (2011). VIV suppression of a two-degree-of-freedom circular cylinder and drag reduction of a fixed circular cylinder by the use of helical grooves. Journal of Fluids and Structures, 27(7), 1124-1133.

[6] Ma, H., Tian, Q., \& Wu, H. (2005). Experimental study of turbulent boundary layers on groove/smooth flat surfaces. Journal of Thermal Science, 14(3), 193-197.

[7] Litvinenko, Y. A., Chernoray, V. G., Kozlov, V. V., Löfdahl, L., Grek, G. R., \& Chun, H. H. (2006, March). The influence of riblets on the development of a $\Lambda$ structure and its transformation into a turbulent spot. In Doklady Physics (Vol. 51, No. 3, pp. 144-147). MAIK Nauka/Interperiodica.

[8] Hadi, A., Wardana, I. N. G., \& Sutikno, D. (2011). The Energy Flux Different Stability Estimation Of Hydraulic Flow in a Horizontal Pipeline With Longitudinal Grooves Number Variation. Rekayasa Mesin, 2(2), 165-174. 
Gufron Saiful Bachri, Rudy Soenoko, Denny Widhiyanuriyawan 